\title{
No Race-Ethnicity Adjustment in CKD-EPI Equations Is Required for Estimating Glomerular Filtration Rate in the Brazilian Population
}

\author{
Amanda D. Rocha, ${ }^{1}$ Suzane Garcia, ${ }^{2}$ Andressa B. Santos, ${ }^{3}$ José C. C. Eduardo, ${ }^{3}$ \\ Claudio T. Mesquita, ${ }^{2,4}$ Jocemir R. Lugon $\mathbb{D}^{1,3}$ and Jorge P. Strogoff-de-Matos $\mathbb{C}^{1,3}$ \\ ${ }^{1}$ Postgraduation Program in Medical Sciences, Fluminense Federal University (UFF), Niterói, Rio de Janeiro, Brazil \\ ${ }^{2}$ Postgraduation Program in Cardiovascular Sciences, Fluminense Federal University (UFF), Niterói, Rio de Janeiro, Brazil \\ ${ }^{3}$ Nephrology Division, Department of Medicine, Fluminense Federal University (UFF), Niterói, Rio de Janeiro, Brazil \\ ${ }^{4}$ Nuclear Medicine Division, EBESERH/Hospital Antonio Pedro, Fluminense Federal University (UFF), Niterói, \\ Rio de Janeiro, Brazil
}

Correspondence should be addressed to Jorge P. Strogoff-de-Matos; strogoff@uol.com.br

Received 26 March 2020; Revised 16 June 2020; Accepted 18 June 2020; Published 18 July 2020

Academic Editor: Danuta Zwolińska

Copyright $\odot 2020$ Amanda D. Rocha et al. This is an open access article distributed under the Creative Commons Attribution License, which permits unrestricted use, distribution, and reproduction in any medium, provided the original work is properly cited.

\begin{abstract}
Background. Glomerular filtration rate (GFR) is usually estimated from equations using serum creatinine (sCr), with adjustment for gender, age, and race (black or nonblack). The Chronic Kidney Disease Epidemiology Collaboration (CKD-EPI) is the preferred equation for adults, but it was validated for the United States population. We intended to evaluate if the race-ethnicity adjustment proposed for the sCr-based CKD-EPI equations is appropriate for the Brazilian population. Methods. CKD outpatients had blood samples collected for determination of sCr and serum cystatin C (sCys) levels. GFR was measured (mGFR) by plasma clearance of ${ }^{51} \mathrm{Cr}$-EDTA and used as the reference. We compared values of mGFR and estimated GFR (eGFR) by CKD-EPI equations based on $\mathrm{sCr}\left(\mathrm{eGFR}_{\mathrm{Cr}}\right)$ and on the combination of $\mathrm{sCr}$ and sCys (eGFR $\left.\mathrm{Cr}_{\mathrm{C}-\mathrm{Cys}}\right)$. For African Brazilian patients, eGFR was calculated either without or with race adjustment. Accuracy was considered acceptable if the difference between the values of eGFR and mGFR was $\leq 30 \%$ (P30). Results. 100 patients were enrolled (58 \pm 14 years, $46 \%$ male, 39\% white and $61 \%$ African Brazilian). Mean mGFR was $46.7 \pm 29.2 \mathrm{ml} / \mathrm{min} / 1.73 \mathrm{~m}^{2}$. Mean $e \mathrm{GFR}_{\mathrm{Cr}}$ and $\mathrm{eGFR}_{\mathrm{Cr}-\mathrm{Cys}}$ without race adjustment were $47.8 \pm 30.1 \mathrm{ml} / \mathrm{min} / 1.73 \mathrm{~m}^{2}$ and $46.4 \pm 30.3 \mathrm{ml} / \mathrm{min} / 1.73 \mathrm{~m}^{2}$, respectively. The corresponding P30 accuracy values were $79.0 \%$ and 83.0\%. In the African Brazilian subgroup, values for mean mGFR and $e_{G F R}$ either without or with race adjustment were $49.8 \pm 32.2 \mathrm{ml} / \mathrm{min} / 1.73 \mathrm{~m}^{2}, 50.4 \pm 32.7 \mathrm{ml} / \mathrm{min} / 1.73 \mathrm{~m}^{2}$, and $58.4 \pm 37.9 \mathrm{ml} / \mathrm{min} / 1.73 \mathrm{~m}^{2}(P<0.001 \mathrm{vs}$. mGFR $)$, respectively. P30 accuracy values for $\mathrm{eGFR}_{\mathrm{Cr}}$ either without or with race adjustment were $75.4 \%$ and $67.2 \%$, respectively. Conclusions. The use of CKD-EPI equations without race-ethnicity adjustment seems more appropriate for the Brazilian population.
\end{abstract}

\section{Background}

Glomerular filtration rate (GFR) is considered the best overall index of kidney function in health and disease [1]. GFR cannot be measured directly but can be assessed as urinary or plasma clearance of exogenous markers such as inulin, iothalamate, 51chromium ethylenediaminetetraacetic acid $\left({ }^{51} \mathrm{Cr}\right.$-EDTA), technetium-labelled diethylenetriamine-pentacetate $\left({ }^{99 \mathrm{~m}} \mathrm{Tc}-\mathrm{DTPA}\right)$, and iohexol [2].
However, these exogenous markers are impractical for routine clinical use because they are expensive and logistically demanding. In clinical practice, GFR is estimated by equations using serum levels of endogenous biomarkers such as serum creatinine (sCr) and cystatin C (sCys) [3]. Despite some limitations [1], $\mathrm{sCr}$ is the most commonly used biomarker for assessing GFR.

The sCr-based equations proposed by the Chronic Kidney Disease Epidemiology Collaboration (CKD-EPI) for adults 
are used worldwide and include a race-ethnicity adjustment for African Americans [4]. Such an adjustment factor was validated for the United States population [5]. However, recent studies suggest that the higher serum creatinine levels reported in blacks in the US and the consequent need for raceethnicity adjustment in creatinine-based GFR equations may not be present in blacks from other countries [6, 7]. In Brazil, the use of race-ethnicity adjustment in the CKD-EPI equations is even more debatable due to the extensive miscegenation of the Brazilian population $[8,9]$.

Our study aimed to evaluate the appropriateness of the race-ethnicity adjustment of the sCr-based CKD-EPI equations for the Brazilian population.

\section{Methods}

2.1. Study Design. This is a cross-sectional study of the performance of CKD-EPI equations for estimation of GFR derived from serum creatinine $\left(e \mathrm{GFR}_{\mathrm{Cr}}\right)$ or combination of serum creatinine and serum cystatin $C\left(e G F R_{C r-C y s}\right)$ in Brazilian patients with chronic kidney disease.

CKD-EPI equations for eGFR $\mathrm{Cr}_{\text {and }}$ eGFR $\mathrm{Cr}_{\mathrm{Cys}}$ calculation were employed with no race-ethnicity adjustment for white subjects, whereas African Brazilians had their eGFR calculated by the same equations, but with and without raceethnicity adjustment (Table 1, Equations 1 and 2). As a reference, GFR was assessed by plasma clearance of ${ }^{51} \mathrm{Cr}$ EDTA and here referred to as measured GFR (mGFR).

A specific form with demographic, anthropometric, and clinical data was fulfilled in the day of GFR measurement. The local ethics committee approved the study. All participants signed the informed consent form.

2.2. Participants. All CKD patients older than 18 years registered at the Nephrology Division Clinics of the University Hospital were eligible to participate in this study. Exclusion criteria were pregnancy, liver cirrhosis, metastatic cancer, paraplegia, quadriplegia, or limb amputation.

2.3. Race-Ethnicity Classification. Participants were classified according to the three main race-ethnicity categories defined by the Brazilian Institute of Geography and Statistics: white, black, and mixed-race. The researcher in charge defined race-ethnicity according to the phenotypic appearance, on the day of GFR measurement. For this study, black and mixed-race subjects were classified into a single group and named as African Brazilians.

2.4. GFR Measurement. The procedures for the assessment of GFR started around 8:00 a.m. at the Nuclear Medicine Unit of the University Hospital. GFR was determined by ${ }^{51} \mathrm{Cr}$-EDTA plasma clearance using the "dose $\times$ decay/interception" method described by Brochner-Motersen [10] and modified by Brandström [11]. GFR was adjusted by body surface using Haycock's formula [12] and expressed in $\mathrm{mL} / \mathrm{min} / 1.73 \mathrm{~m}^{2}$.

First, a cannula was inserted into a forearm vein, and a $10 \mathrm{~mL}$ blood sample was obtained for $\mathrm{sCr}$ and sCys measurement. Next, ${ }^{51} \mathrm{Cr}$-EDTA (3.7 MBq, Amersham, United Kingdom) was injected in bolus (minute 0), and the cannula was flushed with saline and removed. Blood samples $(10 \mathrm{~mL})$ were collected in heparinized tubes from the contralateral upper limb peripheral vein at 150, 195, and 240 minutes for patients with estimated GFR $\geq 30 \mathrm{~mL} / \mathrm{min} /$ $1.73 \mathrm{~m}^{2}$ and 150, 195, 240, and 480 minutes for those with GFR estimated below such threshold. To define whether the duration of the evaluation would be 240 or 480 minutes, GFR was estimated by the CKD-EPI equation using the last sCr value available in the medical record.

Blood samples were centrifuged for 10 minutes at $3000 \mathrm{rpm}$ and separated into two $2 \mathrm{~mL}$ plasma aliquots for ${ }^{51}$ Cr-EDTA counting. Radioisotopic counting lasted 30 minutes on the gamma counter (LB2111-SINASC Multicrystal Gamma, Berthold Technologies, Bad Wildbad, Germany). The value for each point was defined by the average of the two aliquots counting.

2.5. Laboratory. sCr was measured in the Roche/Hitachi Cobas $($ system by the Jaffé method traceable to isotope dilution mass spectroscopy (CREJ2@), Roche Diagnostics GmbH, Mannheim, Germany). sCys was measured in the Siemens BNIIC analyser by nephelometry (Dade Behring $\odot$, Deerfield, IL, USA) and calibrated to the International Federation of Clinical Chemistry Working Group for Standardization of Serum Cystatin C (ERM-DA471/IFCC reference).

2.6. CKD Staging and Concordance between eGFR and $m G F R$. CKD staging based on GFR was defined according the Kidney Disease: Improving Global Outcomes (KDIGO) classification [4]: stage $1, \geq 90 \mathrm{~mL} / \mathrm{min} / 1.73 \mathrm{~m}^{2}$; stage 2,89 to $60 \mathrm{~mL} / \mathrm{min} / 1.73 \mathrm{~m}^{2}$; stage $3 \mathrm{a}, 59$ to $45 \mathrm{~mL} / \mathrm{min} / 1.73 \mathrm{~m}^{2}$; stage $3 \mathrm{~b}, 44$ to $30 \mathrm{~mL} / \mathrm{min} / 1.73 \mathrm{~m}^{2}$; stage 4,29 to $15 \mathrm{~mL} / \mathrm{min} /$ $1.73 \mathrm{~m}^{2}$; and stage $5,<15 \mathrm{~mL} / \mathrm{min} / 1.73 \mathrm{~m}^{2}$.

We also assessed the ability of each equation to correctly classify the patients in the same CKD stage defined by the measured GFR and expressed as the percentage of concordance.

2.7. Performance of the Equations. Equations for GFR estimation had their performance analysed according to bias, precision, and accuracy:

(a) Bias (absolute value) = estimated GFR - measured GFR

(b) Precision $=$ median and interquartile interval of the difference between estimated GFR and measured GFR

(c) Accuracy (P30) = percentage of estimated GFR values with a difference equal to or lower than $30 \%$ of measured GFR

2.8. Statistical Analysis. Differences between measured and estimated GFR were analysed by the Bland-Altman method and expressed in graphs, with measured GFR on the abscissa and the difference (measured-estimated GFR) on the 
TABLE 1: CKD-EPI equations for GFR estimating.

Equation 1: serum creatinine ([5])

\begin{tabular}{lcl} 
Gender & Creatinine $(\mathrm{mg} / \mathrm{dL})$ & \\
Male & $\leq 0.9$ & $\mathrm{GFR}=144 \times(\mathrm{sCr} / 0.9)^{-0.411} \times 0.993^{\text {age }} \times(1.159$ if black $)$ \\
& $>0.9$ & GFR $=144 \times(\mathrm{sCr} / 0.9)^{-1.209} \times 0.993^{\text {age }} \times(1.159$ if black $)$ \\
Female & $\leq 0.7$ & GFR $=141 \times(\mathrm{sCr} / 0.7)^{-0.329} \times 0.993^{\text {age }} \times(1.159$ if black $)$ \\
& $>0.7$ & GFR $=141 \times(\mathrm{sCr} / 0.7)^{-1.209} \times 0.993^{\text {age }} \times(1.159$ if black $)$ \\
\hline
\end{tabular}

Equation 2: combination of serum creatinine and serum cystatin C ([3])

Gender Creatinine $(\mathrm{mg} / \mathrm{dL})$

$\begin{array}{ll}\text { Male } & \leq 0.9 \\ & >0.9 \\ \text { Female } & \leq 0.7 \\ & >0.7\end{array}$

$\mathrm{GFR}=135 \times(\mathrm{sCr} / 0.9)^{-0.207} \times(\mathrm{sCys} / 0.8)^{a} \times 0.995^{\text {age }} \times(1.08$ if black $)$

$\mathrm{GFR}=135 \times(\mathrm{sCr} / 0.9)^{-0.601} \times(\mathrm{sCys} / 0.8)^{a} \times 0.995^{\text {age }} \times(1.08$ if black $)$

$\mathrm{GFR}=130 \times(\mathrm{sCr} / 0.7)^{-0.248} \times(\mathrm{sCys} / 0.8)^{a} \times 0.995^{\text {age }} \times(1.08$ if black $)$

$\mathrm{GFR}=130 \times(\mathrm{sCr} / 0.7)^{-0.601} \times(\mathrm{sCys} / 0.8)^{a} \times 0.995^{\text {age }} \times(1.08$ if black $)$ $a=-0.375$ if sCys $\leq 0.8 \mathrm{mg} / \mathrm{L}$ or -0.711 if $\mathrm{sCys}>0.8 \mathrm{mg} / \mathrm{L}$

GFR, glomerular filtration rate; sCr, serum creatinine; sCys, serum cystatin C.

ordinate, in which negative values indicate GFR overestimation by the equation, whereas positive values mean underestimation.

Normality of data distribution was tested using the Kolmogorov-Smirnov test. Continuous variables are expressed as mean \pm standard deviation in case of a normal distribution or as median (interquartile range), otherwise. Categorical variables are shown as frequencies.

Comparisons between the means were made by paired $t$-test. Frequencies were compared by Fisher's exact test. $P$ values $<0.05$ were considered significant.

Analyses were performed using SPSS ${ }^{\circledR}$ software, version 18.0 for Windows (IBM@, Chicago, IL, USA).

\section{Results}

The general characteristics of the 100 participants are presented in Table 2 . The mean age was $58 \pm 14$ years, and 46 were male. The most common causes of chronic kidney diseases were hypertension, diabetes, and chronic glomerulonephritis. Thirty-nine participants were classified as white and 61 as African Brazilians (27 black and 34 mixedrace).

In the whole group, mGFR was $46.7 \pm 29.2 \mathrm{ml} / \mathrm{min} /$ $1.73 \mathrm{~m}^{2}$. The $\mathrm{eGFR}_{\mathrm{Cr}}$ with no race-ethnicity adjustment was $47.8 \pm 30.1 \mathrm{ml} / \mathrm{min} / 1.73 \mathrm{~m}^{2}(P=0.38$ vs. $\mathrm{mGFR})$, whereas eGFR $_{\mathrm{Cr}}$ including race-ethnicity adjustment was $52.7 \pm 34.9 \mathrm{ml} / \mathrm{min} / 1.73 \mathrm{~m}^{2} \quad(P<0.0001$ vs. $\mathrm{mGFR})$. The eGFR $_{\text {Cr-Cys }}$ without race-ethnicity adjustment was $46.4 \pm 30.3 \mathrm{ml} / \mathrm{min} / 1.73 \mathrm{~m}^{2}$ ( $P=0.70$ vs. $\left.\mathrm{mGFR}\right)$, whereas eGFR $_{\text {Cr-Cys }}$ including race-ethnicity adjustment was $48.8 \pm 32.2 \mathrm{ml} / \mathrm{min} / 1.73 \mathrm{~m}^{2}(P=0.54$ vs. mGFR), Table 3 .

In the subgroup of white participants, mGFR was $41.9 \pm 23.4 \mathrm{ml} / \mathrm{min} / 1.73 \mathrm{~m}^{2}$. The $\mathrm{eGFR}_{\mathrm{Cr}}$ was $43.7 \pm 27.7 \mathrm{ml} /$ $\min / 1.73 \mathrm{~m}^{2}(P=0.26$ vs. $\mathrm{mGFR})$, and $\mathrm{eGFR}_{\mathrm{Cr}-\mathrm{Cys}}$ was $41.6 \pm 27.4 \mathrm{ml} / \mathrm{min} / 1.73 \mathrm{~m}^{2}(P=0.85$ vs. $\mathrm{mGFR})$ (Table 3$)$.

In the African Brazilians subgroup, mGFR was $49.8 \pm 32.2 \mathrm{ml} / \mathrm{min} / 1.73 \mathrm{~m}^{2}$, and it was not significantly different from the white participants. The eGFR $\mathrm{Cr}$ without race-ethnicity adjustment was $50.4 \pm 32.7 \mathrm{ml} / \mathrm{min} / 1.73 \mathrm{~m}^{2}$ ( $P=0.74$ vs. $\mathrm{mGFR}$ ), whereas $\mathrm{eGFR}_{\mathrm{Cr}}$ with race-ethnicity adjustment was $58.4 \pm 37.9 \mathrm{ml} / \mathrm{min} / 1.73 \mathrm{~m}^{2}(P<0.001$ vs. mGFR). The eGFR $\mathrm{Cr}_{\mathrm{Cys}}$ without race-ethnicity adjustment
Table 2: General characteristics of the 100 participants.

\begin{tabular}{lc}
\hline Age (years) & $58 \pm 14$ \\
\hline Male gender, $n(\%)$ & $46(46 \%)$ \\
Race-ethnicity, $n(\%)$ & $39(39 \%)$ \\
White & $61(61 \%)$ \\
$\quad$ African Brazilian & $164 \pm 9$ \\
\hline Height $(\mathrm{cm})$ & $74.9 \pm 15.1$ \\
Weight $(\mathrm{kg})$ & $27.3 \pm 5.4$ \\
Body mass index $\left(\mathrm{kg} / \mathrm{m}^{2}\right)$ & $1.61(1.08-2.33)$ \\
Serum creatinine $(\mathrm{mg} / \mathrm{dL})$ & $1.65(1.11-2.45)$ \\
Serum cystatin C $(\mathrm{mg} / \mathrm{L})$ & \\
\hline Primary renal disease, $n(\%)$ & $31(31 \%)$ \\
Hypertension & $19(19 \%)$ \\
Diabetes & $13(13 \%)$ \\
Chronic glomerulonephritis & $9(9 \%)$ \\
Lupus nephritis & $7(7 \%)$ \\
Chronic pyelonephritis & $4(4 \%)$ \\
Polycystic kidney & $17(17 \%)$ \\
Others &
\end{tabular}

Values are expressed as frequency, mean \pm standard deviation or median (interquartile range).

was $49.4 \pm 31.8 \mathrm{ml} / \mathrm{min} / 1.73 \mathrm{~m}^{2} \quad(P=0.74$ vs. $\mathrm{mGFR})$, whereas eGFR $\mathrm{Cr}$-Cys adding race-ethnicity adjustment was $53.4 \pm 34.4 \mathrm{ml} / \mathrm{min} / 1.73 \mathrm{~m}^{2}(P=0.012$ vs. mGFR) (Table 3$)$.

CKD stages prevalence according to the mGFR were as follows: $9 \%$ in stage G1; $18 \%$ in stage G2; $19 \%$ in stage G3a; $17 \%$ in stage G3b; $24 \%$ in stage G4; and $13 \%$ in stage G5. There was no significant difference between white and African Brazilian participants, but the prevalence of patients with reduced GFR $\left(<60 \mathrm{ml} / \mathrm{min} / 1.73 \mathrm{~m}^{2}\right)$ tended to be higher among whites $(82.1 \%$ vs. $67.2 \%, P=0.11)$ (Table 4$)$.

The rate of patients correctly classified into CKD stages, taking mGFR as reference, varied from $52.5 \%$ of concordance for African Brazilians using eGFR $\mathrm{Cr}_{\text {with }}$ race-ethnicity adjustment to $66.7 \%$ for whites using $e G R_{C r-C y s}$ equation, without statistically significant difference (Table 4). For most of the patients who fell in a stage different from the one they were using the mGFR value, the shifts only occurred between neighbour stages. However, shifts skipping one stage did take place on four occasions when eGFR $_{\mathrm{Cr}}$ equation with race-ethnicity adjustment was used 
TABLE 3: Measured and estimated GFR by CKD-EPI equations, with and without race adjustment.

\begin{tabular}{lccccc}
\hline & $\mathrm{mGFR}^{51}$ Cr-EDTA & $\begin{array}{c}\text { eGFR } \\
\text { (no race } \\
\text { adjustment) }\end{array}$ & $\begin{array}{c}\mathrm{eGFR}_{\mathrm{Cr}} \text { (with race } \\
\text { adjustment) }\end{array}$ & $\begin{array}{c}\mathrm{eGFR}_{\mathrm{Cr}-\mathrm{Cys}} \text { (no race } \\
\text { adjustment) }\end{array}$ & $\begin{array}{c}\mathrm{eGFR} \\
\mathrm{Cr}-\mathrm{Cys} \text { (with race } \\
\text { adjustment) }\end{array}$ \\
\hline $\begin{array}{l}\text { All participants } \\
(n=100)\end{array}$ & $46.7 \pm 29.2$ & $47.8 \pm 30.1$ & $52.7 \pm 34.9^{*}$ & $46.4 \pm 30.3$ & $48.8 \pm 32.2$ \\
$\begin{array}{l}\text { White }(n=39) \\
\begin{array}{l}\text { African Brazilian } \\
(n=61)\end{array}\end{array}$ & $41.9 \pm 23.4$ & $43.7 \pm 27.7$ & - & $41.6 \pm 27.4$ & - \\
\hline
\end{tabular}

Values are expressed as $\mathrm{mL} / \mathrm{min} / 1.73 \mathrm{~m}^{2}$. mGFR: measured glomerular filtration rate; eGFR: estimated glomerular filtration rate; Cr: creatinine; Cys: cystatin C. ${ }^{*} P<0.001$ vs mGFR; ${ }^{* *} P<0.05$ vs mGFR.

TABLE 4: Distribution of patients according to KDIGO classification of CKD staging, based on mGFR and eGFR, and the concordance rate of CKD staging between eGFR and mGFR.

\begin{tabular}{|c|c|c|c|c|}
\hline Method of GFR analysis & & All $(n=100)$ & White $(n=39)$ & African Brazilian $(n=61)$ \\
\hline \multicolumn{5}{|l|}{ mGFR $\left({ }^{51} \mathrm{Cr}\right.$-EDTA $)$} \\
\hline \multirow{6}{*}{ CKD stage } & G1 & $9(9.0 \%)$ & $2(5.1 \%)$ & $7(11.5 \%)$ \\
\hline & G2 & $18(18.0 \%)$ & $5(12.8 \%)$ & $13(21.3 \%)$ \\
\hline & G3a & $19(19.0 \%)$ & $9(23.1 \%)$ & $10(16.4 \%)$ \\
\hline & $\mathrm{G} 3 \mathrm{~b}$ & $17(17.0 \%)$ & $7(17.9 \%)$ & $10(16.4 \%)$ \\
\hline & G4 & $24(24.0 \%)$ & $11(28.2 \%)$ & $13(21.3 \%)$ \\
\hline & G5 & $13(13.0 \%)$ & $5(12.8 \%)$ & $8(13.1 \%)$ \\
\hline \multicolumn{5}{|l|}{ eGFR $_{\mathrm{Cr}}$ (no race adjustment) } \\
\hline \multirow{6}{*}{ CKD stage } & G1 & $12(12.0 \%)$ & $4(10.3 \%)$ & $8(13.1 \%)$ \\
\hline & G2 & $18(18.0 \%)$ & $5(12.8 \%)$ & $13(21.3 \%)$ \\
\hline & G3a & $14(14.0 \%)$ & $4(10.3 \%)$ & $10(16.4 \%)$ \\
\hline & G3b & $20(20.0 \%)$ & $10(25.6 \%)$ & $10(16.4 \%)$ \\
\hline & G4 & $25(25.0 \%)$ & $14(35.9 \%)$ & $11(18.0 \%)$ \\
\hline & G5 & $11(11.0 \%)$ & $2(5.1 \%)$ & $9(14.8 \%)$ \\
\hline Concordance with mGFR (\%) & & $56.0(46.2-65.3)$ & $59.0(43.4-72.9)$ & $54.1(41.7-66.0)$ \\
\hline \multicolumn{5}{|l|}{ eGFR $_{\mathrm{Cr}}$ (with race adjustment) } \\
\hline \multirow{6}{*}{ CKD stage } & G1 & $17(17.0 \%)$ & - & $15(24.6 \%)$ \\
\hline & G2 & $16(16.0 \%)$ & - & $9(14.8 \%)$ \\
\hline & G3a & $14(14.0 \%)$ & - & $10(16.4 \%)$ \\
\hline & G3b & $20(20.0 \%)$ & - & $10(16.4 \%)$ \\
\hline & G4 & $26(26.0 \%)$ & - & $12(19.7 \%)$ \\
\hline & G5 & $7(7.0 \%)$ & - & $5(8.2 \%)$ \\
\hline Concordance with mGFR (\%) & & $55.0(45.2-64.4)$ & & $52.5(40.2-64.5)$ \\
\hline \multicolumn{5}{|l|}{ eGFR $_{\text {Cr-Cys }}$ (no race adjustment) } \\
\hline \multirow{6}{*}{ CKD stage } & G1 & $10(10.0 \%)$ & $3(7.7 \%)$ & $7(11.5 \%)$ \\
\hline & G2 & $20(20.0 \%)$ & $6(15.4 \%)$ & $14(23.0 \%)$ \\
\hline & G3a & $8(8.0 \%)$ & $2(5.1 \%)$ & $6(9.8 \%)$ \\
\hline & G3b & $25(25.0 \%)$ & $10(25.6 \%)$ & $15(24.6 \%)$ \\
\hline & G4 & $29(29.0 \%)$ & $15(38.5 \%)$ & $14(23.0 \%)$ \\
\hline & G5 & $8(8.0 \%)$ & $3(7.7 \%)$ & $5(8.2 \%)$ \\
\hline Concordance with mGFR (\%) & & $64.0(54.2-72.7)$ & $66.7(50.9-79.4)$ & $62.3(49.7-73.4)$ \\
\hline \multicolumn{5}{|l|}{ eGFR $_{\text {Cr-Cys }}$ (with race adjustment) } \\
\hline \multirow{6}{*}{ CKD stage } & G1 & $14(14.0 \%)$ & - & $11(18.0 \%)$ \\
\hline & G2 & $16(16.0 \%)$ & - & $10(16.4 \%)$ \\
\hline & G3a & $12(12.0 \%)$ & - & $10(16.4 \%)$ \\
\hline & G3b & $22(22.0 \%)$ & - & $12(19.7 \%)$ \\
\hline & G4 & $29(29.0 \%)$ & - & $14(23.0 \%)$ \\
\hline & G5 & $7(7.0 \%)$ & - & $4(6.6 \%)$ \\
\hline Concordance with mGFR (\%) & & $62.0(52.2-70.9)$ & & $59.0(46.5-70.5)$ \\
\hline
\end{tabular}

mGFR: measured glomerular filtration rate; eGFR: estimated glomerular filtration rate; Cr: creatinine; Cys: cystatin C. Frequencies are expressed by number (percentage), and concordance between CKD stages as percentage (95\% confidence interval).

and one occasion each when every other formula was utilized.

The P30 accuracy of eGFR $\mathrm{Cr}_{\text {r }}$ and $\mathrm{eGFR}_{\mathrm{Cr}-\mathrm{Cys}}$ equations for all patients with no race-ethnicity adjustment was $79.0 \%$ and $83.0 \%$, respectively. When race-ethnicity adjustment was added in the equations, P30 accuracy of eGFR $\mathrm{Cr}$ and eGFR $_{\text {Cr-Cys }}$ was $74.0 \%$ and $82.0 \%$, respectively (Table 5 and Figure 1). 
TABLe 5: Performance of the equations for estimation of GFR.

\begin{tabular}{|c|c|c|c|c|}
\hline & $\mathrm{eGFR}_{\mathrm{Cr}}$ (no race adjustment) & $\begin{array}{c}\mathrm{eGFR}_{\mathrm{Cr}} \\
\text { (with race adjustment) }\end{array}$ & $\begin{array}{c}\text { eGFR }_{\text {Cr-Cys }} \\
\text { (no race adjustment) }\end{array}$ & $\begin{array}{c}\text { eGFR }_{\text {Cr-Cys }} \\
\text { (with race adjustment) }\end{array}$ \\
\hline \multicolumn{5}{|c|}{$\operatorname{Bias}\left(\mathrm{mL} / \mathrm{min} / 1.73 \mathrm{~m}^{2}\right)$} \\
\hline All participants & $0.1(-6.5-7.1)$ & $2.8(-1.9-11.0)^{\mathrm{a}}$ & $-0.1(-6.2-4.0)$ & $1.6(-3.7-5.5)^{\mathrm{b}}$ \\
\hline White & $0.7(-5.6-7.8)$ & - & $0.4(-5.6-4.8)$ & - \\
\hline African Brazilian & $-0.5(-8.1-5.9)$ & $3.2(-0.5-14.3)^{\mathrm{a}}$ & $-0.2(-7.1-3.0)$ & $2.4(-2.2-5.8)^{\mathrm{b}}$ \\
\hline \multicolumn{5}{|c|}{ Precision $\left(\mathrm{mL} / \mathrm{min} / 1.73 \mathrm{~m}^{2}\right)$} \\
\hline All participants & $6.8(3.2-11.9)$ & $6.3(2.2-12.2)$ & $5.1(2.0-10.7)^{\mathrm{c}}$ & $4.5(2.3-10.3)^{\mathrm{d}}$ \\
\hline White & $6.3(3.5-11.1)$ & - & $4.8(2.1-8.4)$ & - \\
\hline African Brazilian & $7.4(3.0-13.3)$ & $5.5(2.0-14.3)$ & $5.5(2.0-11.4)$ & $4.3(2.4-11.8)$ \\
\hline \multicolumn{5}{|l|}{ Accuracy (P30) } \\
\hline All participants & $79.0(70.0-85.9)$ & $74.0(64.6-81.6)$ & $83.0(74.3-89.2)$ & $82.0(73.2-88.4)$ \\
\hline White & $84.6(69.9-93.1)$ & - & $87.2(72.8-94.9)$ & - \\
\hline African Brazilian & $75.4(63.2-84.6)$ & $67.2(54.7-77.7)$ & $80.3(68.5-88.5)$ & $78.7(66.7-87.2)$ \\
\hline
\end{tabular}

eGFR: estimated glomerular filtration rate; Cr: creatinine; Cys: cystatin C. Bias and precision are expressed as median (interquartile range), and accuracy as percentage $\left(95 \%\right.$ confidence interval). ${ }^{a} P<0.0001$ vs. eGFR $\mathrm{Cr}_{\mathrm{r}}$ without race adjustment and $\mathrm{eGFR}_{\mathrm{Cr}-\mathrm{Cys}}$ without race adjustment; ${ }^{\mathrm{b}} P<0.0001$ vs. eGFR ${ }_{\mathrm{Cr}-\mathrm{Cys}}$ without race adjustment; ${ }^{c} P=0.013$ vs. $\mathrm{eGFR}_{\mathrm{Cr}}$ without race adjustment; ${ }^{\mathrm{d}} P=0.005$ vs. $\mathrm{eGFR}_{\mathrm{Cr}}$ with race adjustment.

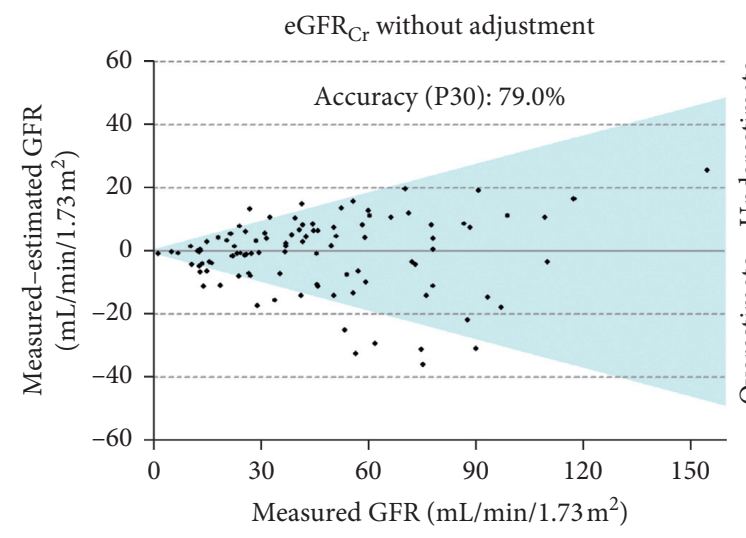

(a)

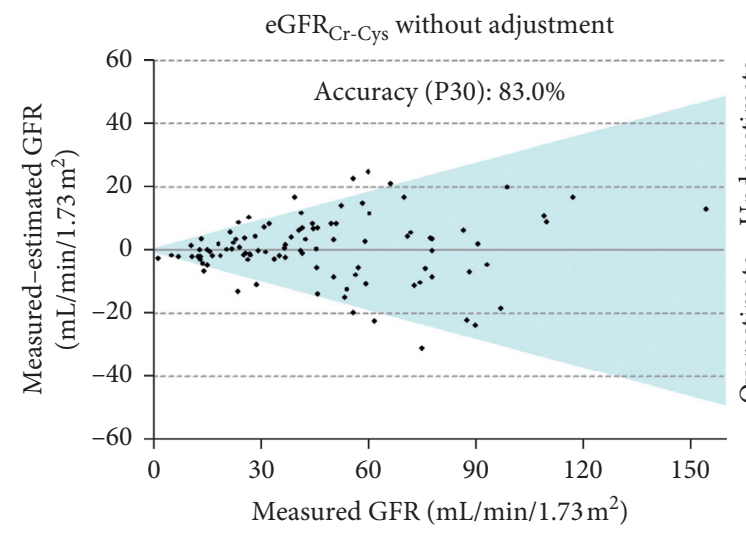

(c)

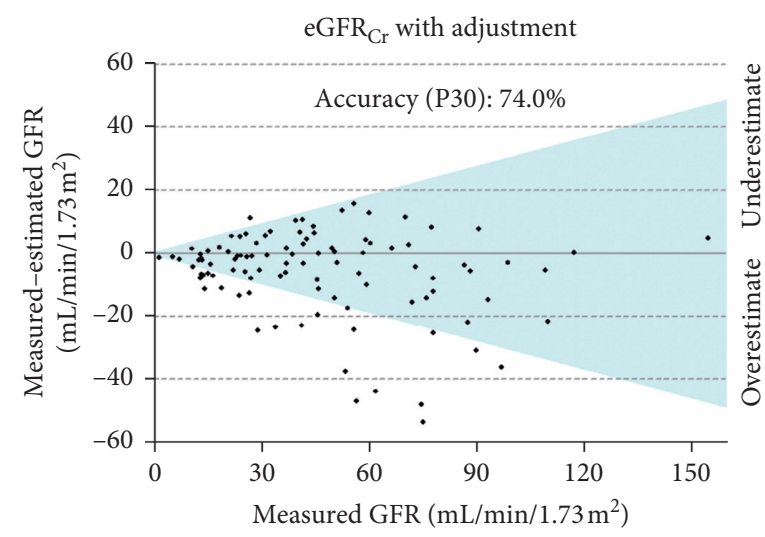

(b)

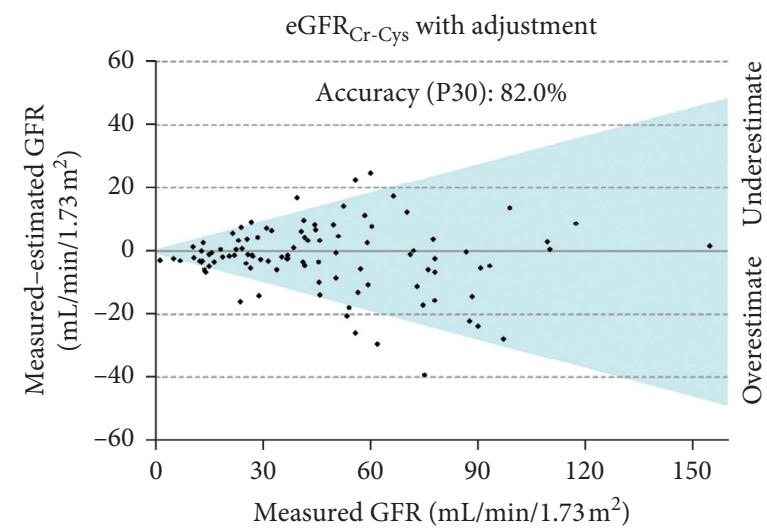

(d)

Figure 1: Accuracy of CKD-EPI equations for all participants $(n=100)$, in which dots inside the colour area mean a difference between measured and estimated GFR lower than 30\% (P30).

In the white participants' subgroup, P30 accuracy of $e G F R_{C r}$ and $e G R_{C r-C y s}$ equations was $84.6 \%$ and $87.2 \%$, respectively (Table 5 and Figure 2).

In the African Brazilian subgroup, the P30 accuracy values for $e^{-G F R} R_{C r}$ and $e G F R_{C r-C y s}$ equations with no race-ethnicity adjustment were $75.4 \%$ and $80.3 \%$, respectively. When accounting for the race-ethnicity adjustment, P30 accuracy of $e^{-G F R}$ Cr and $e G_{F}$ Cr-Cys equations was $67.2 \%$ and $78.7 \%$, respectively (Table 5 and Figure 3). 


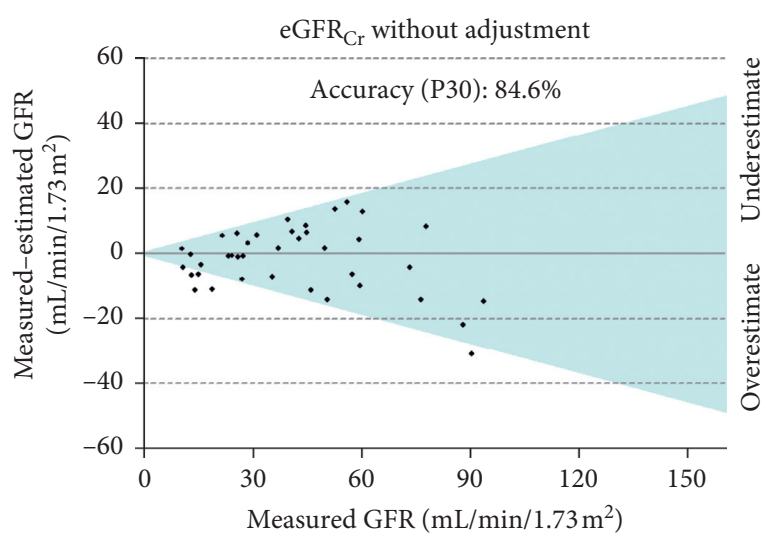

(a)

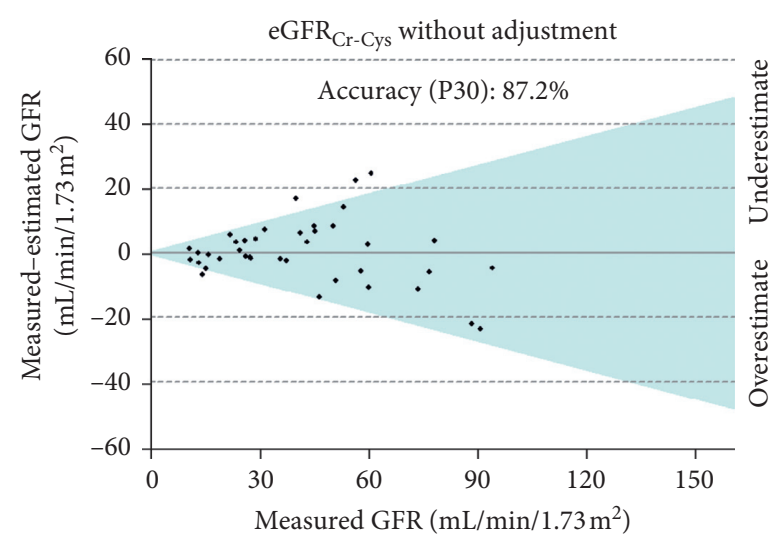

(b)

FIgURe 2: Accuracy of CKD-EPI equations for white participants $(n=39)$, where dots inside the colour area mean a difference between measured and estimated GFR lower than $30 \%$ (P30).

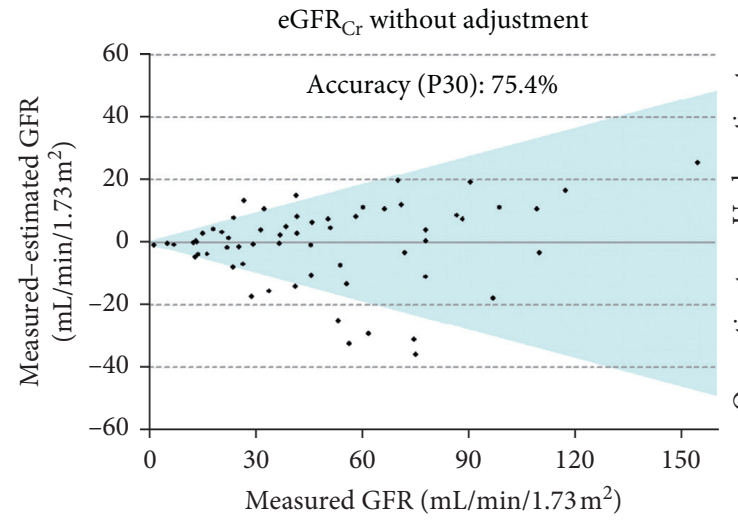

(a)

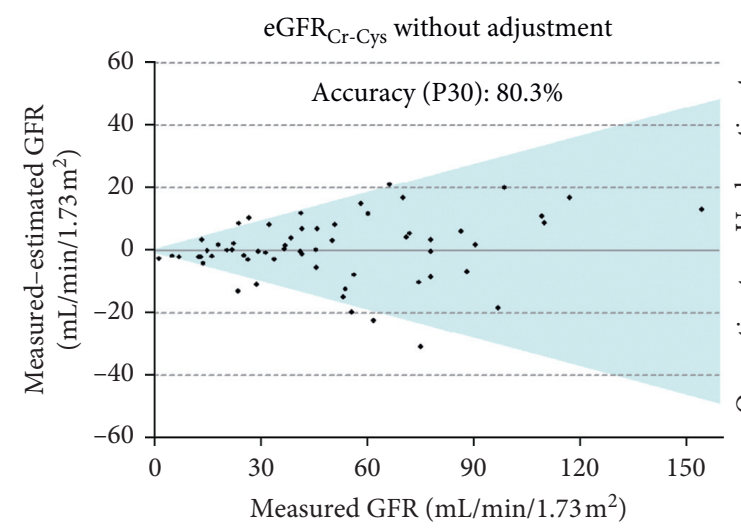

(c)

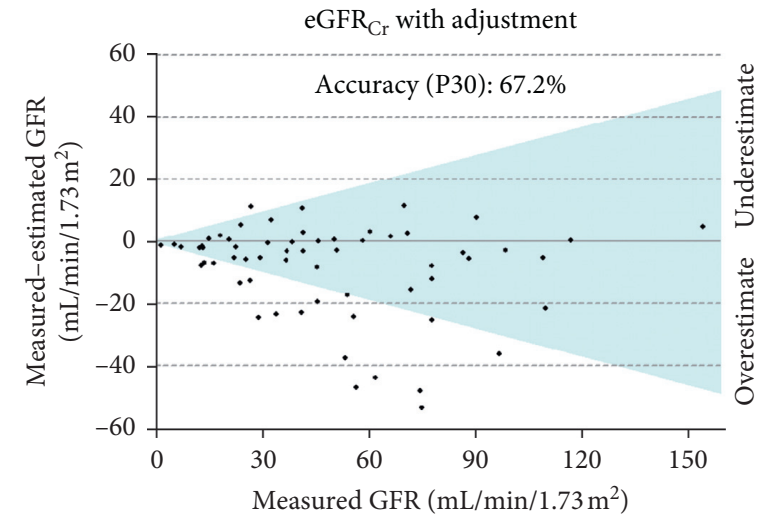

(b)

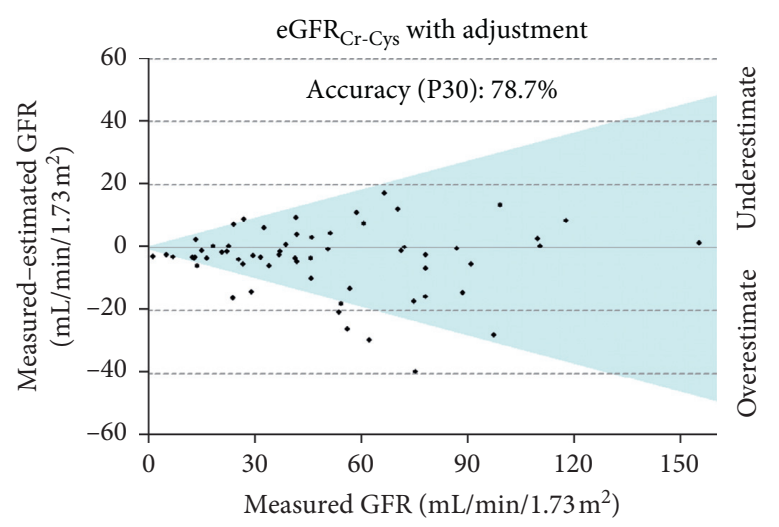

(d)

FIgUre 3: Accuracy of CKD-EPI equations for African Brazilians $(n=61)$, where dots inside the colour area mean a difference between measured and estimated GFR lower than 30\% (P30).

In the whole group, the precision of eGFR $\mathrm{Cr}_{\mathrm{C}-\mathrm{Cys}}$ equations, without or with race-ethnicity adjustment, was higher than creatinine-only equations (Table 5). The absolute bias $\left(\mathrm{mL} / \mathrm{min} / 1.73 \mathrm{~m}^{2}\right)$ of eGFR $\mathrm{Cr}$ equation without race-ethnicity adjustment for all patients, whites, and African Brazilians were $0.1,0.7$ and -0.5 , respectively. The correspondent bias $\left(\mathrm{mL} / \mathrm{min} / 1.73 \mathrm{~m}^{2}\right)$ of the $\mathrm{GFFR}_{\mathrm{Cr}-\mathrm{Cys}}$ equation without race-ethnicity adjustment was $-0.1,0.4$, and -0.2 . After the inclusion of race-ethnicity adjustment, there was a significant increase in the bias of both eGFRCr and eGFRCrCys equations for all participants and the subgroup of African Brazilians (Table 5).

The performance of the equations was not significantly different when patients with $\mathrm{mGFR}<60 \mathrm{~mL} / \mathrm{min} / 1.73 \mathrm{~m}^{2}$ or 
$\geq 60 \mathrm{~mL} / \mathrm{min} / 1.73 \mathrm{~m}^{2}$ were studied separately. However, the P30 accuracy was numerically higher among participants with $\mathrm{mGFR} \geq 60 \mathrm{~mL} / \mathrm{min} / 1.73 \mathrm{~m}^{2}$ for all equations (Table 6).

\section{Discussion}

Our study aimed to evaluate the performance of CKD-EPI equations for estimating GFR and the pertinence of raceethnicity adjustment. To date, there have been no studies designed to answer such questions in the Brazilian population. Our findings suggest that the original CKD-EPI equations can be used in the Brazilian population, presenting an acceptable performance and a smaller bias if used with no race-ethnicity adjustment in African Brazilians.

Our findings are consistent with what we could expect if we critically review the history of the development of those equations in the United States and the description of their performance in other populations, such as sub-Saharan Africans.

Firstly, Levey et al. [13], in 1999, published the equations they developed from the Modification of Diet in Renal Disease (MDRD) study data. However, only patients previously diagnosed with $\mathrm{CKD}$ were enrolled in that clinical trial, and racial and ethnic minorities were underrepresented. In those equations, a race-ethnicity adjustment of 1.212 was added for blacks. Given the limitations of the MDRD equations, the Chronic Kidney Disease Epidemiology Collaboration consortium proposed new equations in 2009. Such new equations were developed and validated from data gathered from 10 different studies and were externally validated in participants from 16 other studies, including individuals with normal GFR and a greater racial and ethnic diversity [5]. Using the sCr-based CKD-EPI equations, the race-ethnicity adjustment for blacks was 1.159. Thus, for individuals of the same age, sex, and sCr, the estimated GFR will be $15.9 \%$ higher for blacks compared to individuals of other races and ethnicities. However, such race adjustment, in a binary fashion (black or nonblack), was validated only for the US population. Further studies suggest that the peculiarity of higher serum creatinine values found in African Americans and therefore the need to add a raceethnicity adjustment may not be appropriate to blacks from other countries. Flamant et al. [14] studied 302 African Europeans who were pair-matched with white Europeans for mGFR $\left({ }^{51} \mathrm{Cr}\right.$-EDTA renal clearance), age, gender, body mass index, and body surface area. They found that CKD-EPI equation with the African American race-ethnicity correction factor overestimated GFR in African Europeans. Nonetheless, African Europeans had serum creatinine 8\% higher than their matched white Europeans, suggesting that a lower race-ethnicity correction is needed. In a recent study, Bukabau et al. [7] analysed the applicability of several estimating equations in sub-Saharan African populations. Using plasma clearance of iohexol as the reference, they found that both the Modification of Diet in Renal Disease and CKD-EPI equations performed better without the race coefficient. In fact, CKD-EPI equation without race adjustment and the Full Age Spectrum equation (FAS), a recently developed equation, which does not have a racial component, had the best performance in participants with normal GFR, whereas the FAS equation had a smaller bias and higher accuracy in those with GFR below $<60 \mathrm{~mL} / \mathrm{min} /$ $1.73 \mathrm{~m}^{2}$.

In a previous study conducted in São Paulo, Brazil, the creatinine-based MDRD and CKD-EPI equations, with raceethnicity and no race-ethnicity adjustment, were compared to the measured GFR by iohexol plasma clearance in 244 patients followed at a glomerulopathy outpatient clinic. The authors have found no increase in accuracy by adding raceethnicity adjustment in the equations. However, only $8 \%$ of patients were African Brazilians [15].

Our finding of more unsatisfactory performance of equations by adding race-ethnicity adjustment indeed did not come as a surprise for us. In a previous study, our group analysed 1,303 individuals living in the city of Niterói, Rio de Janeiro, and 33\% self-classified as white, $41 \%$ as brown, and $26 \%$ as black. In that analysis, we found no differences in serum creatinine values between the race groups, even after stratification by sex and age ranges, raising the question of whether adding race-ethnicity adjustment to eGFR equations would be appropriate for our population. However, the absence of measured GFR weakened our conclusions [9]. Those findings motivated the development of the present study so that we could confirm this hypothesis.

If the use of race-ethnicity adjustment had improved the performance of eGFR equations in our study, probably its routine adoption at the clinical practice in Brazil would not be an easy task. Brazilian population has an ethnic composition made up of an extensive mixture of three different ancestral roots: Europeans, sub-Saharan Africans and, to a lesser extent, Native Americans [8]. This mixture generated a considerable variability of skin pigmentation shade, with no discontinuity between dark and pale skin colour. Thus, the high degree of miscegenation in the population would make the adding of race-ethnicity adjustment to eGFR equations even more questionable.

The use of new equations that are not dependent on a race/ethnicity variable could solve this issue and be adopted worldwide and for different ethnical groups. The FAS equation seems a very promising alternative, since it is based on normalized $\mathrm{SCr}(\mathrm{s} \mathrm{Cr} / \mathrm{Q})$, in which $Q$ is the median $\mathrm{sCr}$ from healthy populations to account for gender and age. Thus, the FAS equation can be used indistinctly in children, adolescents, adults, and elderly, obviating the need of specific equations for each phase of life [16]. Later, new FAS equations were developed, incorporating cystatin $\mathrm{C}$ alone or the combination of sCr and cystatin C [17]. Even though FAS equations were validated for Caucasians only, the study of Bukabau et al. [7], with 494 participants from Democratic Republic of Congo and Ivory Coast, showed that both FAS and CKD-EPI equations without race-ethnicity adjustment had the best performance in those with normal GFR, whereas FAS equation had a smaller bias and higher accuracy in the individuals with GFR below $<60 \mathrm{~mL} / \mathrm{min} / 1.73 \mathrm{~m}^{2}$.

Another critical issue that deserves discussion would be the necessity and convenience of developing specific eGFR equations for the Brazilian population. Our findings suggest that this would not be needed since the 
TABle 6: Performance of the equations according to the range of measured GFR using the threshold of $60 \mathrm{~mL} / \mathrm{min} / 1.73 \mathrm{~m}$.

\begin{tabular}{lcccc}
\hline & $\begin{array}{c}\mathrm{eGFR}_{\mathrm{Cr}} \text { (no race } \\
\text { adjustment) }\end{array}$ & $\begin{array}{c}\mathrm{eGFR}_{\mathrm{Cr}} \text { (with race } \\
\text { adjustment) }\end{array}$ & $\begin{array}{c}\mathrm{eGFR}_{\mathrm{Cr}-\mathrm{Cys}} \text { (no race } \\
\text { adjustment) }\end{array}$ & $\begin{array}{c}\mathrm{eGFR}_{\mathrm{Cr}-\mathrm{Cys}} \text { (with race } \\
\text { adjustment) }\end{array}$ \\
\hline GFR $\geq 60 \mathrm{~mL} / \mathrm{min} / 1.73 \mathrm{~m}^{2}(\mathrm{n}=27)$ & & & & \\
Bias $\left(\mathrm{mL} / \mathrm{min} / 1.73 \mathrm{~m}^{2}\right)$ & $-4.0(-11.3-14.6)$ & $5.5(-2.6-21.8)^{\mathrm{a}}$ & $-3.6(-11.8-10.2)$ & $2.4(-3.8-15.5)^{\mathrm{b}}$ \\
Precision $\left(\mathrm{mL} / \mathrm{min} / 1.73 \mathrm{~m}^{2}\right)$ & $12.1(8.3-19.7)$ & $11.6(4.2-21.8)$ & $11.0(5.5-20.0)$ & $8.7(3.1-17.3)$ \\
Accuracy $(\mathrm{P} 30)$ & $85.2(66.9-94.7)$ & $77.8(58.9-89.7)$ & $85.2(66.9-94.7)$ & $88.9(71.1-97.0)$ \\
\hline GFR $<60 \mathrm{~mL} / \mathrm{min} / 1.73 \mathrm{~m}^{2}(n=73)$ & & & & \\
Bias $\left(\mathrm{mL} / \mathrm{min} / 1.73 \mathrm{~m}^{2}\right)$ & $0.1(-4.9-6.4)$ & $1.8(-1.8-7.4)^{\mathrm{a}}$ & $0.1(-4.1-2.4)$ & $1.5(-3.6-3.7)^{\mathrm{b}}$ \\
Precision $\left(\mathrm{mL} / \mathrm{min} / 1.73 \mathrm{~m}^{2}\right)$ & $5.5(1.6-9.2)$ & $5.6(1.8-10.5)$ & $3.4(1.7-8.2)$ & $3.5(2.2-7.8)$ \\
Accuracy $(\mathrm{P} 30)$ & $76.7(65.7-85.0)$ & $72.6(61.4-81.6)$ & $82.2(71.7-89.4)$ & $79.5(68.7-87.2)$ \\
\hline
\end{tabular}

eGFR: estimated glomerular filtration rate; Cr: creatinine; Cys: cystatin C. Bias and precision are expressed as median (interquartile range), and accuracy as percentage ( $95 \%$ confidence interval). ${ }^{a} P<0.0001$ vs. eGFRCr without race adjustment and eGFR ${ }_{\text {Cr-Cys }}$ without race adjustment; ${ }^{b} P<0.05$ vs. eGFR ${ }_{\text {Cr-Cys }}$ without race adjustment.

performance of the equations, with no race-ethnicity adjustment, was quite satisfactory, being just slightly more imperfect than that described in the original validation studies, with a little lower accuracy but no significant bias. The performance of creatinine-based CKD-EPI equations with no race-ethnicity adjustment was also similar to CKD-EPI equations using both $\mathrm{sCr}$ and sCys. Furthermore, the Brazilian population is substantially racially diverse, whereas countries in which specific equations were developed or adapted in order to improve the performance had a very homogeneous population, such as Japan [18]. Thus, we believe that the development of a bespoken equation for the Brazilian population only would be justified if there were a significant bias or the accuracy were unacceptably lower, which was not the case in our study.

Our study presents several limitations, including the small sample size and the geographical restriction of the studied population who probably is not representative of the whole Brazilian population.

In conclusion, the performance of CKD-EPI equations is acceptably good and can be used in the Brazilian population, and no race-ethnicity adjustment in creatinine-based CKDEPI equations seems necessary and could indeed worsen the performance of the equations. Additional studies enrolling a broader number of patients are desirable to confirm our findings.

\section{Data Availability}

The datasets analysed during the current study are available from the corresponding author on reasonable request.

\section{Ethical Approval}

The project was approved by the research ethics committee of the Department of Medicine, Universidade Federal Fluminense, Niterói, RJ, Brazil (approved project number: CAAE 46535215.8.0000.5243).

\section{Consent}

All participants gave written consent.

\section{Conflicts of Interest}

All authors declare no conflicts of interest.

\section{Authors' Contributions}

A.D.R. was responsible for study design, data collection and organization, provision of study patients, data analysis, manuscript writing, and final approval of the manuscript. S.G.F. was responsible for study design, data collection and organization, data analysis, and final approval of the manuscript. A.B.S. was responsible for data collection and organization, data analysis, and final approval of the manuscript. J.C.C.E. was responsible for study design, provision of study patients, analysis of the data, and final approval of the manuscript. C.T.M. was responsible for study design, data collection and organization, analysis of the data, and final approval of the manuscript. J.R.L. and J.P.S.M. were responsible for conception and design of the study, organization, data analysis, manuscript writing, and final approval of the manuscript.

\section{Acknowledgments}

This study was financially supported by the Coordenação de Aperfeiçoamento de Pessoal de Nível Superior (CAPES), Ministry of Education, Brazil.

\section{References}

[1] A. S. Levey, J. Coresh, H. Tighiouart, T. Greene, and L. A. Inker, "Measured and estimated glomerular filtration rate: current status and future directions," Nature Reviews Nephrology, vol. 16, no. 1, pp. 51-64, 2020.

[2] I. Soveri, U. B. Berg, J. Björk et al., "Measuring GFR: a systematic review," American Journal of Kidney Diseases, vol. 64, no. 3, pp. 411-424, 2014.

[3] L. A. Inker, C. H. Schmid, H. Tighiouart et al., "Estimating glomerular filtration rate from serum creatinine and cystatin C," New England Journal of Medicine, vol. 367, no. 1, pp. 20-29, 2012.

[4] Kidney Disease: Improving Global Outcomes (KDIGO) CKD Work Group, "KDIGO 2012 clinical practice guideline for the evaluation and management of chronic kidney disease," Kidney International, vol. 3, no. 1, pp. 1-150, 2013. 
[5] A. S. Levey, L. A. Stevens, C. H. Schmid et al., "A new equation to estimate glomerular filtration rate," Annals of Internal Medicine, vol. 150, no. 9, pp. 604-612, 2009.

[6] H. E. v. Deventer, J. A. George, J. E. Paiker, P. J. Becker, and I. J. Katz, "Estimating glomerular filtration rate in black South Africans by use of the modification of diet in renal disease and Cockcroft-Gault equations," Clinical Chemistry, vol. 54, no. 7 , pp. 1197-1202, 2008.

[7] J. B. Bukabau, E. Yayo, A. Gnionsahé et al., "Performance of creatinine- or cystatin C-based equations to estimate glomerular filtration rate in sub-Saharan African populations," Kidney International, vol. 95, no. 5, pp. 1181-1189, 2019.

[8] M. F. Lima-Costa, L. C. Rodrigues, M. L. Barreto et al., "Genomic ancestry and ethnoracial self-classification based on 5,871 community-dwelling Brazilians (the epigen initiative)," Scientific Reports, vol. 5, Article ID 9812, 2015.

[9] R. C. d. B. Barcellos, J. P. S. d. Matos, H. C. Kang, M. L. G. Rosa, and J. R. Lugon, "Comparison of serum creatinine levels in different color/race categories in a Brazilian population," Cadernos de Saúde Pública, vol. 31, no. 7, pp. 1565-1569, 2015.

[10] J. Bröchner-Mortensen and P. Rödbro, "Optimum time of blood sampling for determination of glomerular filtration rate by single-injection $\left[{ }^{51} \mathrm{Cr}\right]$ EDTA plasma clearance," Scandinavian Journal of Clinical and Laboratory Investigation, vol. 36, no. 8, pp. 795-800, 1976.

[11] E. Brändström, A. Grzegorczyk, L. Jacobsson, P. Friberg, A. Lindahl, and M. Aurell, "GFR measurement with iohexol and ${ }^{51} \mathrm{Cr}$-EDTA. A comparison of the two favoured GFR markers in Europe," Nephrology Dialysis Transplantation, vol. 13, no. 5, pp. 1176-1182, 1998.

[12] G. B. Haycock, G. J. Schwartz, and D. H. Wisotsky, "Geometric method for measuring body surface area: a heightweight formula validated in infants, children, and adults," The Journal of Pediatrics, vol. 93, no. 1, pp. 62-66, 1978.

[13] A. S. Levey, J. P. Bosch, J. B. Lewis, T. Greene, N. Rogers, and D. Roth, "A more accurate method to estimate glomerular filtration rate from serum creatinine: a new prediction equation," Annals of Internal Medicine, vol. 130, no. 6, pp. 461-470, 1999.

[14] M. Flamant, E. Vidal-Petiot, M. Metzger et al., "Performance of GFR estimating equations in African Europeans: basis for a lower race-ethnicity factor than in African Americans," American Journal of Kidney Diseases, vol. 62, no. 1, pp. 182184, 2013.

[15] J. A. Zanocco, S. K. Nishida, M. Tiveron Passos et al., "Race adjustment for estimating glomerular filtration rate is not always necessary," Nephron Extra, vol. 2, no. 1, pp. 293-302, 2012.

[16] H. Pottel, L. Hoste, L. Dubourg et al., "An estimated glomerular filtration rate equation for the full age spectrum," Nephrology Dialysis Transplantation, vol. 31, no. 5, pp. 798806, 2016.

[17] H. Pottel, P. Delanaye, E. Schaeffner et al., "Estimating glomerular filtration rate for the full age spectrum from serum creatinine and cystatin C," Nephrology, Dialysis, Transplantation: Official Publication of the European Dialysis and Transplant Association-European Renal Association, vol. 32, no. 3, pp. 497-507, 2017.

[18] M. Horio, E. Imai, Y. Yasuda, T. Watanabe, and S. Matsuo, "Performance of GFR equations in Japanese subjects," Clinical and Experimental Nephrology, vol. 17, no. 3, pp. 352-358, 2013. 